\title{
¿QUÉ PASA CON LA PASTORAL VOCACIONAL? REVISIÓN DE LA PASTORAL VOCACIONAL EN LA IGLESIA
}

DOI: https://doi.org/10.52039/seminarios.v52i181.646

Autor: Mikel Garciandía Goñi. Diócesis de Pamplona-Tudela.

Son dos ponencias que tuvo en el Encuentro de Delegados de Pastoral Vocacional. Nos invita a hacer un diagnóstico de la realidad de nuestra PV, a que nos preguntemos por la fuerza de nuestra propuesta. Teniendo en cuenta las "debilidades" de la fe en las que podemos caer.

\section{INTRODUCCIÓN}

Los pasados 27, 28 y 29 de septiembre, una treintena de delegados de pastoral vocacional de toda España nos reunimos en el XXVII encuentro anual. Invitados por la Comisión Episcopal de Seminarios y Universidades, nos dedicamos a poner en marcha una reflexión acerca del momento en el que nos encontramos en la Iglesia en la pastoral vocacional. Se trata de ver a qué nos está llamando Dios en estos momentos de cara a mejorar esta importante tarea nuestra. Para una revisión de la pastoral vocacional, pensamos conveniente elaborar unas pautas comunes que puedan iluminar el esfuerzo y trabajo que todos llevamos adelante en nuestras diócesis.

Publicamos ahora las dos reflexiones que se ofrecieron los días 27 y 28 de septiembre, así como las cuestiones suscitadas en el grupo de trabajo al hilo de ellas. 
Os proponemos que leáis y reflexionéis estas dos ponencias, para entender mejor el trasfondo de las preguntas y cuestionamientos que ofrecemos al final. Éstas, podéis trabajarlas con todos los que colaboran más directa o indirectamente en la promoción vocacional, con vuestras comunidades cristianas, delegaciones de pastoral familiar, catequesis, juventud, congregaciones, movimientos, etc.

Tenemos como plazo hasta el día de S. José, para que enviemos nuestras respuestas al cuestionario que entre todos elaboramos, y a finales del curso, se os adjuntarán las conclusiones elaboradas en forma de síntesis, como un documento de trabajo que pueda ser un punto de partida para ajustar y relanzar la pastoral vocacional en la medida de las posibilidades y necesidades de cada uno.

\section{Explicación de los títulos de las ponencias}

El título que pretende ser "pro-vocador". No sabemos si pasa o no pasa algo en la pastoral vocacional. Si debe o no debe pasar nada. Si conviene "hacer mudanza" aunque estemos en tiempo de desolación, al menos cultural. Se propone "una sacudida", "salto cualitativo en esta encrucijada histórica" (Nuevas vocaciones para una nueva Europa. In verbo tuo'..., n. 13).

También quizá podemos hablar de una cierta desolación en lo psicológico, o mejor, en lo anímico. Estos meses Dios nos puede regalar el afrontar con buena conciencia lo que vivimos y hacemos en el tema vocacional. Esa desolación implica ausencia de suelo firme, el que no haya una consistencia, una garantía, unas certidumbres preestablecidas. Sabemos que nuestra misión nos pide no sólo acompañar los procesos de los jóvenes que se plantean una especial consagración a Dios, sino también a mantener un planteamiento netamente vocacional de la vida, en la Iglesia y para el mundo de hoy.

En su momento, la comisión y el delegado del encuentro decidieron que era momento oportuno para dar al encuentro de este año un sesgo diferente. Por ello han propuesto a Mikel Garciandía que este año, entre todos, tratemos de entrar un poco más a fondo en cuestiones que vayan más allá de lo operativo, que aborden a fondo el tema de manera global, en lugar de tratar uno u otro aspecto de la pastoral vocacional.

\footnotetext{
${ }^{1}$ A partir de aquí citamos el documento como nvnE.
} 
Ese tipo de método habitual empleado estos años nos ha sido muy útil a los que en las distintas diócesis recibíamos la encomienda de hacer, coordinar y animar la propuesta vocacional. Nosotros en Pamplona siempre hemos vuelto a casa estimulados a ir un poco más allá en nuestro trabajo, al compartir y enriquecernos con la vida de otras diócesis mejor organizadas y con más experiencia en toda esta pastoral. Más allá del sentimiento que a veces acecha de sentir todo esto como un tener que sacar adelante una encomienda engorrosa y difícil, vamos a dar un paso más, que tiene que ver con lo anímico y lo espiritual. Yo quisiera que la pregunta que flotara en el ambiente fuera la de:

¿Qué nos pide Dios aquí y ahora a quienes nos dedicamos a la pastoral vocacional, a la animación, coordinación... de quienes son llamados por el Señor?

Frente a la patología del cansancio... interrogantes oportunos, revisión de eventuales errores y fallos (nvnE, n.13). En el documento redactado al final de congreso europeo sobre las vocaciones se pedía abordar de verdad la cuestión vocacional. Este documento será el referente principal de estas reflexiones que siguen.

El título de estas jornadas alude en esta línea, a esta pretensión de escuchar de verdad la voluntad de Dios. Precisamos que nuestra conciencia se remueva en nosotros, que colaboramos con el Espíritu en la tarea de que en nuestras comunidades cristianas se viva de forma natural y radical el hecho de que hoy Cristo llama a cada uno.

Por ello empleamos la palabra revisión, en el sentido genuino de volver a mirar, y así volver a ver si es que hay que cambiar algo, mucho o todo lo que hacemos, o quizás nada, solo que hay que cambiar el desde dónde y cómo vivimos y situamos lo que ya hacemos. No se trata del mero innovar, sino releer entre todos las claves magisteriales y teológicas desde las que ajustar no sólo nuestro trabajo, sino también el trabajo y la conciencia vocacional de nuestras iglesias.

Ir ahora más allá supone atender la realidad de la vocación cristiana. Supone también escuchar lo que desde la antropología teológica y teología fundamental se puede decir para que toda llamada de Dios pueda germinar y crecer sana. Por ello, estos días y los próximos meses os invito a que nos preguntemos cómo podemos hoy ayudar a quien se encuentra con que el seguimiento a Cristo conlleva una elección y decisión muy concreta. 
Documento nuevas vocaciones para una Europa, sería importante retomarlo. In verbo tuo, en tu palabra echaré las redes. Tal es el subtítulo del documento, que subraya de modo claro la acción de Dios, en cuya Palabra nos lanzamos mar adentro.

\section{Razones para una revisión}

Por eso, tenemos que aclarar en primer lugar que no estamos aquí para juzgar lo que estamos haciendo, y por tanto, para tratar de justificarnos y ponernos a la defensiva.

Se nos propone evaluar mirando más allá, insistiendo en que no se trata de justificar meramente la encomienda recibida. Probablemente lo que hacemos es todo lo que podemos hacer, y seguro que está bien.

Es otra cosa. Es pararnos, y ponernos a preguntar mirando al futuro:

¿Son estas las iniciativas que en nuestra diócesis, comunidad... darán respuesta de aquí a veinte años a lo que el Señor nos pide?

A los delegados de la pastoral vocacional la Iglesia nos pide algo más. Si el día a día nos encierra en una pastoral inmediatista, de urgencias, caigo y caemos en una miopía. Debemos mirar mejor.

Los años cincuenta, fueron de reclutamiento, identidades netas, la transmisión no ofrecía problemas.

Los años setenta, de inserción en la realidad social emergente, de la inculturación, la secularidad, el diálogo ante unos cambios sorprendentemente rápidos.

Los años noventa, han sido los de la identidad, propuesta explícita de la fe cristiana al mundo. Pero hoy nos queda un camino por recorrer.

Hay una pregunta que puede pesarnos, pero que es bueno formularla en voz alta:

¿Con estas iniciativas que sacamos adelante año a año, queda garantizada la "vocacionalidad" de la Iglesia de las próximas dos décadas?

\section{METODOLOGÍA}

Se trata de llegar a un documento. Las dos ponencias pueden servir como base y trasfondo para perfilar las preguntas que proponemos a todas nuestras diócesis. Trabajo nace de aquí, y es para todos, los que forman parte de nuestros equipos, etc. 


\section{Trabajo en el encuentro}

Debatimos, nos planteamos las grandes cuestiones pendientes.

2. Elaboración del cuestionario

A lo largo de estos dos días, y especialmente en el tercer momento de trabajo por grupos, y en la cuarta reunión de todos, llegamos a unas cuestiones básicas para proponer en cada diócesis.

\section{Trabajo por diócesis}

De octubre a marzo, respondemos al secretariado con las conclusiones, respuestas, itinerarios...

\section{Elaboración de unas pistas operativas}

Hacemos una síntesis los encargados de ello, y la reenviamos a todas las diócesis. En el documento figurará el número de diócesis y personas que han participado, para mostrar el peso del documento.

Finalmente lo hacemos llegar a cada diócesis. 


\section{"COMUNIDAD CRISTIANA Y VOCACIÓN: DEBILIDADES Y POSIBILIDADES” (I)}

“Muchachos, ¿tenéis pescado?” (Jn 21,5)

Comenzamos con una pregunta del Señor, muy oportuna, aunque suscite como respuesta, no aquella tan rotunda de los apóstoles, sino el cierto pudor eclesial, necesidad de salvar la cara, dolor de lo que nos falta, de lo que no tenemos. Este es el pescado que tenemos, o simplemente, un rotundo "no tenemos pescado".

Con esta pregunta queremos ir más allá de si tenemos los candidatos para suplir huecos eclesiales. Queremos preguntarnos cómo promover la "nueva cultura vocacional en los jóvenes y en las familias" (Juan Pablo II).

\section{NECESIDAD DE UN DIAGNÓSTICO ENTRE TODOS}

\section{La pastoral vocacional, actividad unida al ser de la Iglesia}

El documento nuevas vocaciones para una nueva Europa, en el número 25 postula nítidamente la centralidad de la pastoral vocacional. El peligro consiste en el montar la pastoral desde unas grandes frases, que al final quedan vacuas, pues el Magisterio si no es rumiado, queda o bien vacío y abstracto, o bien muy pesado (ejemplo de la pastilla de caldo concentrado de carne que no puede ser directamente masticada, sino que ha de añadirse al agua caliente para poder ser asimilada).

¿Dónde queda la Iglesia real y concreta, la comunidad diocesana, parroquial, la familia, el grupo en nuestro trabajo vocacional? Sin toda la riqueza de la vida comunitaria, queda tocada y debilitada nuestra labor. Hace falta todo el sustrato eclesial para que cada hombre y mujer se plantee toda la vida como un seguir radical a Cristo, hay que recuperar esa relación entre los elementos de la vida cristiana para que la pregunta vocacional fragüe: la comunidad creyente, clima de fe, de comunión de amor, de madurez espiritual, el valor del anuncio, la intensidad de la vida sacramental (cfr. nvnE, n. 19).

Acostumbrados a los estereotipos, y aquejados por muchas inercias, aspiramos a que no nos saquen de nuestras casillas, estrechas por otro 
lado. Es siempre ese desconocido el que pregunta: "muchachos, ¿tenéis pescado?".

Y nosotros añadimos a esa pregunta: ¿Conservamos fresco ese momento de la pesca? ¿A mí, quién y cuándo y cómo me pescó? ¿Qué pescadores de hombres han pasado junto a mí en el camino de la vida?

Somos los primeros que hemos de creer eso de que la pastoral unitaria se funda en la vocacionalidad de la Iglesia (nvnE, n. 25).

Eso que a mí me con-movió y me con-mocionó en su momento, ¿Qué es y cómo lo vivo y cómo lo llevo yo ahora en "mi” propuesta vocacional?

¿Acaso los que me ayudaron a seguir a Cristo no eran hombres y mujeres vinculados muy directamente a la suerte de su comunidad y su Iglesia?

Esta pesca de la Pascua remite a otra primera pesca, en la que Pedro se ve sobrepasado, sorprendido. Fiado de sus palabras, una vez más hemos de echar las redes.

Nuestro echar las redes, ¿desde dónde lo hacemos? ¿qué relación tenemos con toda la diócesis?

$P V$, perspectiva originaria de la pastoral general (nvnE, n.26).

Pero, ¿no será eso una hipótesis inocua de trabajo? (nvnE, n.26).

¿De qué lado de la barca y a qué hora? ¿La más oportuna, la más apropiada? ¿La más segura?

Fiados en tus palabras, Señor...

¿Dónde radica la fuerza de "nuestra" propuesta?

Quizá en que precisamente no es nuestra, sino de toda la Iglesia, y de nosotros agentes pastorales en y desde ella.

Debemos acoger las preguntas incómodas pues son la más saludables, son salvadoras.

Hay que dar forma a postulados como son los de pasar de una pastoral de experiencias, hacia una pastoral de itinerarios. Del nomadismo o del vagabundeo, o del turismo, pasar al peregrinaje. ¿En qué consiste todo esto?

\section{Debilidades de nuestra situación cultural}

El nihilismo es más sutil de lo que creemos, pues más allá de una visión del mundo es un virus que deja a la persona sin gramática elemental de la existencia (nvnE, n. 11). 
Nuestra cultura ambiental puede llegar a ser corrosiva (¿tenemos y ofrecemos antídotos?): panteón a-jerárquico, débil capacidad proyectiva de la vida, (nvnE, n. 11).

Capacidad de discernimiento cultural : descubrir la raíz ambivalente y pagana de ciertos esquemas mentales y afectivos (nvnE, n. 35).

La situación nos puede llevar a caer en unas dicotomías pobres, en el sentido de o bien negociamos a la baja, o nos metemos en nuestro bastión. Nuestro tiempo requiere ejercer una efectiva caridad cultural, (nvnE, n.12). Ella supera la pereza, inercia, indolencia, miopía cultural. Es una buena pregunta ver en qué consisten esas patologías en nosotros, y cómo sanarlas con una genuina caridad cultural.

Se da un debilitamiento y poca valoración de lo que se hace "vocacionalmente" (médico, profesor o consagrado, que aspiran a ser buenos profesionales...).

A ello se añaden las debilidades de los lugares pedagógicos (grupo, comunidad, escuela, familia) (nvnE, n. 30). La pastoral vocacional depende también de la solidez de estas instituciones.

\section{Debilidades de nuestra fe}

¿Por qué determinadas teologías y praxis vocacionales no producen vocaciones mientras que otras sí las producen? (nvnE, n. 11). Esta pregunta hemos de abordarla con seriedad. Proponemos algunas pistas.

La crisis de la sociedad y de cada ser humano ya no disuelve meramente los contenidos de la fe (fides quae creditur), sino la posibilidad misma del acto de creer (fides qua creditur). Nosotros tenemos el deber de detectar y eliminar los bloqueos que impiden la experiencia del sentido pleno y religioso de la vida.

El empeño de la modernidad por construirse un sentido, una morada segura (mos-moris, que está en el origen de moral y morada) fracasa una y otra vez: Frankl explica el porqué de ello:

«El sentido ha de ser encontrado, pero no puede ser producido. Lo que puede ser producido es o un sentido subjetivo, o una simple sensación de sentido, o ... el absurdo. Así se comprende que el hombre que no es ya capaz de encontrar un sentido a su vida, como tampoco de inventarlo, busque la manera de refugiarse de su creciente sentimiento de falta de sentido ya en el absurdo, ya en un sentido subjetivo», V. FRANKL, La presencia ignorada de Dios, Barcelona 1986, 102. 
Los planteamientos puramente prometeicos, en los que la razón y la voluntad humanas se sitúan en el centro mismo de la realidad constituyen una ideología. El encontrar el sentido supone creer en una verdad que nos trasciende, y a la que hay que prestar toda nuestra atención. La actitud de escucha profunda es básica para no terminar creyendo en nosotros mismos, y fiándolo todo a nuestra subjetividad. En este sentido, la pobreza cultural hace que seamos poco marianos y muy de Zacarías. Nos cuesta el ¿cómo ha de ser eso?, y nos quedamos en el ¿cómo sabré yo que...? Nos resulta una trampa difícil de sortear la de la subjetividad.

Ello hace que instrumentalicemos absolutamente todo, hasta la propia religión.

«Nos encontramos en un ambiente cultural en que la religión, en muchos casos, se conserva sólo en apariencia, pues la hemos ido transformando en un estímulo para la vida secular y antropocéntrica, en una garantía de la humanidad del mundo, en una forma mágica de dominar nuestro mundo, dejando de ser de esta manera una religión verdaderamente religiosa» (Don Fernando Sebastián).

En esa línea de purificar la propia fe, resulta importante distinguir la imagen social de la creencia con la verdadera fe. Creencia y credulidad no son lo mismo.

«Es casi imposible diferenciar la fe de su imitación social. Tanto más cuanto que puede haber en el alma una parte de fe auténtica y otra de imitación de la fe. Es casi imposible pero no imposible. En las actuales circunstancias, rechazar la imitación social es quizá para la fe una cuestión de vida o muerte», S. WEIL, A la espera de Dios. Nos lo decía esta inquieta autora espiritual hace más de medio siglo. Y Madeleine Delbrêl, en un texto dirigido a un obispo, en 1960:

"La mentalidad de nuestro ambiente superpone sus evidencias sobre las certezas de la fe: da la impresión de que, incluso sin fe, creeríamos en Dios, tendríamos convicciones cristianas por fidelidad familiar, o por tradición regional o nacional.

De ello resulta un conocimiento confuso y desigual de las realidades sobrenaturales:

- confuso, porque distinguimos mal las realidades de la fe de las evidencias de nuestra mentalidad;

- desigual, porque tenemos distinto grado de conocimiento de las realidades de la fe, en función de si conciernen o no a nuestra vida práctica 
lo que nuestras condiciones de vida no nos ayudan a recordar escapa a nuestra atención

Damos por supuesto lo genuino de nuestro creer, sin profundizar en todos los sentidos de la palabra:

- Creemos que Él es (credere Deum)

- Le creemos cuando nos dice que... (credere Deo)

- La fe (credere in Deum)

La fe en los tres sentidos:

- Creer lo que no vimos (Hb 11)

- La respuesta del hombre al Dios que se revela: obediencia de la fe (CIC 143)

- Participación en la fe de Cristo (Hb 12,2): entrar en la relación del Hijo con el Padre, pues Cristo es el sí, el que inicia y consuma nuestra fe.

La conversión debe ser un cuestionamiento para el agente de pastoral, continuamente expuesto a una pregunta implícita muy radical. No tanto la de ¿crees en Dios?, sino más bien ¿desde qué Dios vives?

Asimismo, damos por supuesto que la oración se da, pero de ahí a que el estilo de nuestra pastoral sea orante, va un paso.

Papel de la confesión de fe, que testimonia la propia opción (nvnE, n. 34). No basta testimoniar en abstracto, puesto que Dios es lo máximamente personal y personalizador. Quedarse en ese plano externo puede ser el drama de muchos padres, que no han podido transmitir la fe, y tal vez nunca han manifestado a sus hijos explícitamente cómo su vivir, luchar, optar había sido desde Dios).

Si no vamos respondiendo a la llamada a la conversión, hacemos de la pastoral un sucedáneo. Cuidado con la ideologización y uso abstracto de la metanoia, como un mero cambio de mentalidad. Se trata de un cambio en sentido de la conversio, cum-vertere, volverse hacia lo que Cristo reclama, dejando de lado lo que propone "el mundo" en el sentido paulino del término.

Don Fernando: «Casi se oye únicamente la recomendación de que los cristianos acojamos con buen ánimo la cultura del momento. Hay que decir también que debemos acogerla de manera activa y creadora, ofreciendo las posibilidades de discernimiento, de crítica y de creatividad que 
la fe nos otorga. Vivir pasivamente, aceptando de buena o mala gana lo que nos sobreviene, además de ser una falta de correspondencia con el Señor, es tacañería y deslealtad con nuestros conciudadanos, a quienes privamos de los bienes que nos vienen de unos dones recibidos también para su servicio» ${ }^{2}$. Sobran los comentarios.

\section{Debilidades de nuestra situación eclesial}

Des-ideologizar la fe implica recuperar la visión mística, es decir, la visión de la Realidad oculta en ella. La ideología es un mecanismo que inmuniza de la realidad, pero que cae en una unilateralidad empobrecedora.

Podemos tomar la fe como subcultura o como una verdadera cultura y matriz cultural generadora de vida, que se sitúa más allá de los planteamientos inmediatistas. Alguna pista para ver esto:

Michael Paul Gallagher reduce lo que él denomina las respuestas cristianas a la cultura a tres, de las que son rechazables las dos primeras: hostilidad ansiosa hacia la cultura y aceptación ingenua. Ante ellas, se privilegia una tercera vía, que consiste en el discernimiento de las actitudes ${ }^{3}$. En cuanto a las dos primeras, resumiendo todavía más, ambas actitudes ocultan una misma incapacidad para aceptar la bidireccionalidad de la comunicación humana cuando realmente se trata de comunicación, abierta a escuchar lo que los receptores dicen, para que la comprensión mejore por ambas partes, y esa relación resulte fecunda. Esta incapacidad de escucha muestra la fragilidad de quien teme acceder a una novedad que pueda trastocar una postura que entiende como definitiva. Pero el creyente en Jesucristo atiende y espera la irrupción de lo Nuevo, no de lo ya conocido de sobra.

Ponemos el ejemplo de alguna dicotomías:

Residual $>$ resto

Se hace imprescindible distinguir lo que es una identidad puramente residual, inercial, arqueológica, de lo que es ser un resto vivo, que mantiene una memoria transformadora del mundo.

\footnotetext{
${ }^{2}$ Nueva evangelización. Fe, cultura y política en la España de hoy, 27

3 Cfr. Fede e Cultura, 163-167.
} 


\section{Exilio nostálgico > éxodo esperanzado}

Hay que curar el sentimiento de derrota, y descubrir que incluso el exilio es una ocasión para que las distintas familias de Israel retomen con mayor pasión y pureza la confianza en las promesas del Señor, que ya se están cumpliendo aquí y ahora, contra viento y marea, incluso con nuestra pobre colaboración... Si estamos en Babilonia y ya no en Jerusalén, será necesario preparar continuamente el retorno a la Patria.

Crustáceo > vertebrado

Podemos usar la energía vital para acorazarnos por fuera, blindarnos, o para vertebrar toda nuestra existencia en torno a la Palabra de Verdad que nos constituye y renueva desde dentro hacia fuera.

\section{Moralista > Místico}

«El Dios de Jesucristo, el Dios que se da a conocer por medio de Jesucristo en el Espíritu Santo, es la última determinación escatológica y definitiva de la apertura indeterminada del hombre; y es también, en consecuencia, la respuesta cristiana a la situación del ateísmo moderno. Así, la predicación del Dios trino posee, justamente en la situación actual, una importancia pastoral extrema», W. KASPER, El Dios de Jesucristo, 357.

Además de esas dicotomías, está la necesidad de la unidad de los creyentes para que el mundo crea. No pueden nacer vocaciones allí donde no se vive un espíritu auténticamente eclesial (nvnE, n. 29). No nos fiamos a menudo de nuestros compañeros, ellos tampoco de nosotros. Queda en entredicho la Iglesia Madre que vela y llama (reglas para sentir en la Iglesia, de Ignacio de Loyola).

El religioso que con tres años de profesión lo deja, el matrimonio que a los seis meses se separa, el cura que no ve sentido a lo que hace, o es incapaz de valorarlo... Se da una enorme indefinición que parte de un error de fondo, o mejor, de una falta de enraizamiento real en las fuentes de la vida.

\section{Ambigüedades de la "propuesta vocacional"}

El documento lo dice de manera taxativa; la crisis de las vocaciones es crisis de los que llaman (nvnE, n. 19).

El creyente quien, en virtud de su fe, debe en cierto modo hacerse cargo de la vocación del otro (presbiteros, consagrados, padres, catequistas, educadores... (nvnE, n. 26). 
Gratuidad en la llamada, interés desinteresado, y no un desinterés muy interesado. Amor espiritual, es el modo en el que el Espíritu ama en nosotros. El Espíritu está haciendo presente a Cristo y al Padre, a quienes podemos invocar como kyrios y como Abba.

Problema de que les "mentimos" al anunciarles la vocación, y no se les prepara para el mundo que realmente van a encontrarse.

A las parejas que se casan...

A los seminaristas, no sé hasta qué punto no les miento, como formador del seminario, si no les preparo para entrar a este presbiterio y a esta diócesis, o a quien entra en una congregación religiosa, se le hace ver que el volumen de lo que hay que mantener en pie (obras de tamaño ingente, con cada vez menos gente...) va a repercutir en su vivencia concreta de su consagración a Dios. ¿Se elabora la realidad de la cruz? El decir a quien acompañamos: "debes renunciar a ti, negarte, vivir la radicalidad del seguimiento...".

\section{De pastoral de experiencias a pastoral de itinerarios}

Esta expresión del congreso que da origen al documento "Nuevas vocaciones para una nueva Europa"

Ir más allá de la trampa del subjetivismo, del pietismo, de una fe a la carta (denuncia del Papa en Colonia...). No conformarnos con la pastoral de sacramentalización, sino formar de verdad en los elementos que vertebran la vida del creyente.

Imitar a Jesucristo no es lo mismo que seguirle. El verdadero creyente no se conforma con ajustarse a un pretendido patrón conductual, sino que desde los ojos de la fe mira al mundo y a sí mismo, e inicia una verdadera peregrinación espiritual, absolutamente inédita, y a la vez en perfecta sintonía eclesial.

Los tres últimos Papas (con pontificados largos....) nos pueden servir de guía, y aunque la riqueza de matices que nos ofrecen es enorme, nos puede servir este sencillo esquema:

\section{Juan XXIII: acogida cordial}

Pablo VI: diálogo sincero

\section{Juan Pablo II: propuesta valiente}


«La dialógica busca sobre todo las condiciones de posibilidad de una comunidad de comunicación ideal; en otros términos, se trataría de la comunicación en tanto que funda o debe fundar la comunión entre los participantes. Se refiere primordialmente a los sujetos que participan en esa cosa o realidad que es la comunicación. Pero ésta es algo más que un intercambio verbal de pensamiento o simple relación lingüística. Persigue una participación real en aquello que uno tiene y es. La verdadera comunidad de comunicación surge, en consecuencia, allí donde la participación y comunicación verbal pasan a ser una autocomunicación» (H. Waldenfels, Teología fundamental contextual). El credo del Deuteronomio parte de la propia vida: mi padre era un arameo errante... Dt 25, 5-10).

Desde ahí es posible articular correctamente el "estar en el mundo sin ser del mundo", yendo más allá de dicotomías parciales. El principio de secularidad, tan central en el cristianismo, no significa cesión o flojera de lo escatológico. La esperanza como virtud teologal ha de ser vivida con claridad. Somos ciudadanos del cielo.

Una pastoral de experiencias, puede convertirse en una pastoral de urgencias. No todo el que está con Jesús sirve para la vocación específica. Desde la urgencia del "todos valen", confundimos el hecho de que el anuncio de Jesús llega a todos, con el otro factor de que no sirven todas las respuestas de las personas para lo mismo. El enfermo que ha sido curado, el de la Decápolis (Mc 5, 20), ha de quedarse "en su casa", y no va con Jesús.

Es una debilidad de nuestra situación, la cantidad de cristianos que estamos situados en sitios muy seguros y plausibles, pero quizá por eso poco creíbles. Un cristianismo que pretende ser plausible meramente, se vacía de lo específico suyo. Es imposible encajar siempre en la lógica del mundo, sin que el escándalo tome a veces la primacía en nuestro relacionarnos con el mundo.

\section{Concluyendo mi intervención primera...}

Estamos allá donde ya nada parece que puede acontecer. Los peces son abrasados por este sol inclemente y se han metido en honduras a las que no llegan nuestras redes. Sólo cabe fiarnos de la Palabra y volver a salir una y otra vez para que el Señor siga convocando y reuniendo a las ovejas dispersas, a los extraviados, a tantos a quienes el Espíritu ya está disponiendo para que se acerquen a nosotros y poder escuchar al Pastor. 
"PARA QUE LAS VOCACIONES DE DIOS RESUENEN Y HALLEN RESPUESTA”(II)

“Todavía salió a eso de la hora undécima...” (Mt 20, 6)

La hora undécima, es esa hora en la que ya nada puede acontecer. Símil de la pesca que usábamos ayer, puede completarse con el de la parábola de los trabajadores de la viña. El dueño llama tanto a primera como a última hora. Sólo el gozo de una paga grande para todos le anima a seguir llamando a cualquier hora, más allá de los cálculos y las expectativas.

\section{HACIA UN PRONÓSTICO ENTRE TODOS}

Al final se trata de extraer conclusiones válidas para nuestras realidades.

Hay resonadores activados y otros desactivados que propician o dificultan nuestra labor. Hay sordinas que mitigan e incluso apagan la voz de Dios. Persona como máscara teatral, cuya función es per-sonare, hacer resonar la Palabra. Cuestión de cómo ser verdaderamente resonadores. Pregunta incómoda de cómo te ayudo o si te ayudo a que escuches la voz de Cristo cuando te hablo.

\section{1. ¿De qué vocaciones se habla?}

Al hablar de vocaciones, en el sentido más genuino (y profundo) de llamadas de Dios. En plural, puesto que son tantas como personas y muy variadas.

Hay quien teme que la ampliación del concepto de vocación pueda perjudicar a la específica promoción de las vocaciones al sacerdocio y a la vida consagrada; en realidad sucede exactamente lo contrario (nvnE, n. 26).

Trascender el planteamiento de una búsqueda de las vocaciones de especial consagración, que recrea los dos géneros de cristianos de la edad media. Hay que profundizar en la cuestión yendo más allá de la funcionalidad, entrando en lo antropológico profundo. El amor, vocación fundamental e innata de todo ser humano (Juan Pablo II, Familiares Consortio, 11). 
El Espíritu Santo, artista interior que modela con creatividad infinita el rostro de cada uno según Jesús (nvnE, n. 18). La vocación es llegar a la verdad de lo que somos, no un mero apéndice operativo que nos marca el hacer más que el ser.

\section{Resonadores activados y desactivados}

Hablamos de resonadores desactivados cuando un joven, influido por el ambiente piensa que Dios no está

- En el dolor

- En mi realizarme

- En mi autonomía

La tarea de la pastoral vocacional, mostrar la incongruencia y las carencias en la gente que nos llega. Nos apoyamos para nuestro trabajo sobre unos supuestos y sustratos humanos que luego no se dan. Hay que tener en cuenta el pasado, la biografía de quien llama a nuestras puertas.

Se precisa la apologética frente al ateo, pero una dialógica concreta ante el indiferente, ante el postmoderno, que no sea acomodaticia. Ante el dilema de escoger el Reino o el mundo, no tratar de negociar. No engañarnos a la hora de mostrar las "pérdidas" del seguimiento.

\section{La comunión}

"Testimonio coral, Iglesia toda vocacional, todos son animadores vocacionales" (nvnE, n. 6). O todos podemos resultar des-animadores. La coralidad de la pastoral vocacional implica el convencimiento de que quien evangeliza es toda la Iglesia, y no un sector de ella. Hemos de vivir de manera con-corde y unánime. Sólo así animamos y tenemos la fuerza necesaria para conmocionar el mundo.

Sin capacidad de comunión, no se puede entender a Cristo, pues uno trata de imponer "lo suyo", sino de ofrecer en fidelidad el don recibido, del que no podemos adueñarnos.. Desde una vida impositiva a otra propositiva, pero más exigente. La finalidad de los carismas, la común utilidad (1 Cor 12, 7) (nvnE, n. 15)

La pastoral vocacional ha de conllevar grupos de integración, comunión, no absolutistas, juzgadores.

¿Realmente nos creemos que caben todos en la barca de Pedro? 
¿Hemos aprendido a trabajar en comunión? O cada uno se cree con derecho para decir dónde está Dios, hay más garantías, hay más seguridad...

\section{Que sean uno}

Identidad cristiana, trinitaria.

Unas vocaciones complementan y completan a las demás. Lo personal se vive desde la comunión, desde lo comunitario, sin falsas contraposiciones. No es posible hablar unilateralmente y sobre todo de los aspectos diferenciadores sin mostrar cómo en la Iglesia lo esencial es lo común.

\section{La minoridad}

Es habitual caer en el tono lastimero, de lamento ante la dureza de la situación actual. Pero quizá hay un tema de fondo más grave. Más allá de los resultados más o menos escasos que nuestros esfuerzos cosechan, hemos de preguntarnos si creemos en la esterilidad. Estamos caducos, poco cabe esperar y es ahora cuando Dios puede mostrar su brazo fuerte.

- Nos falta crear una sicología de minoría (Ratzinger lo dijo en Pamplona, y don Fernando lo recordó en sus catequesis de Colonia). La minoridad de caminar hacia Babilonia en un destierro cultural que puede ser largo, pero que exige juntarnos, preservar lo esencial... Una sicología de mayoría nos hace aún daño, puesto que nos hace caminar con inercias ideológicas, y no cesa de crear una mala conciencia. Ser minoría (hablo de lo cualitativo más que de lo cuantitativo, aunque también...) exige una mística fuerte, y vivir esa vocación "mañanera" que habla el documento de "nuevas vocaciones...".

- El lamento niega la lógica de Dios. ¿Dejamos los delegados, agentes, colaboradores de pastoral vocacional que la lógica de Dios se desarrolle? En los años 50 este planteamiento resultaría extraño, y hasta absurdo, puesto que, viendo los resultados "vocacionales", parecería no ser necesario cambiar nada ni ir más al fondo en los planteamientos.

En los años 70 hubo que revisar el triunfalismo, y el riesgo fue una excesiva invisibilización de identidades y un cierto complejo de inferioridad (o de superioridad, que viene a ser lo mismo).

Años 90, jubileo del 2000, esperar en la lógica de Dios. ¿Quién reconoce a Dios? Simeón, Ana, Zacarías, Isabel... Dios entra por la estéril, vieja, que ha perdido el vigor, que ha renunciado a sus hijos. 
Síndrome de Zacarías, que queda mudo por una torpe pregunta, y que sólo cuando renuncia a que su hijo sea otro Zacarías, puede proclamar la alegría de la paternidad de Juan el Bautista...

Juan el Bautista profetiza a un Cristo que viene, y que me dice "conviértete", pues de lo contrario te pierdes el reconocerlo como "el que viene".

Michel Shabbah, patriarca latino de Jerusalén, el 10 de agosto, a un grupo de peregrinos, nos dijo que la Iglesia de Jerusalén, entonces y ahora es pequeña, pero ahí está manteniendo fiel memoria del Resucitado.

\section{Teología y pedagogía}

Se habla de secularismo, de una nueva secularidad, más dura y corrosiva por lo sutil y atractiva. Dios queda reducido a un plano lejano y abstracto, y en nombre de una presunta teología de la muerte de Dios, damos por bueno al Dios ausente (Varone), y no planteamos de verdad la cuestión de un Deus absconditus.

En el Nuevo Testamento aparece Cristo como Camino, Verdad y Vida. Queda por realizar una fenomenología concreta de qué significa eso objetivo para hoy y nosotros. Hay que integrar el hecho de que Cristo sea Verdad y Vida, con el de que a su vez se muestre como el Camino. El qué y el cómo en Cristo son lo mismo.

Actitudes pedagógicas evangélicas: sembrar, acompañar, educar, formar, discernir (nvnE, nn. 33-38)

La mostaza es la semilla más pequeña, y al no creernos esto del todo nos quejamos porque "nosotros sólo tenemos una vocación..." ¿Nos creemos que una persona puede transformar el mundo?

\section{Falsas dicotomías (identidad y relevancia...)}

No podemos seguir estando en una situación de falsas dicotomías. O identitarios o abiertos. Lo fácil es caer en ser cristianos de identidad fuerte y cerrada, o de identidad abierta pero débil.

Estar en el mundo sin ser del mundo. Lo decisivo de nosotros creyentes es la fuente de la que brota nuestra vida. Nos alimentamos de otra cosa, y ello no implica superioridad y prepotencia, sino asombro ante el regalo que permanentemente recibimos de Dios. 
La alegría cristiana ¿consiste acaso en ser como los demás?

Infantilismo y falsa madurez (cerrazón e incapacidad para escuchar una voz discordante de mi discurso...). Nos asusta ser como niños e infantilizamos esa alegría, a la vez que somos agresivos con lo que vivimos como amenazante. "Este es de los..." Hoy urge un desarme unilateral.

\section{Eficacia y fecundidad}

El triunfalismo trae necesariamente el derrotismo como consecuencia puesto que ambos salen de una misma mentalidad.

El eficacismo debe dar paso a una manera serena e intensa de trabajar (vivir con tranquilidad: 1Tes 4,11).

No es lo mismo aspirar a resultados, y funcionar en una lógica de eficacia humana, que esperar a que en el nombre de Dios suceda según El ha dicho. Hemos sido llamados a dar frutos, pero eso se da si uno está enraizado en las entrañas de Cristo (Cfr. Jn 15)

\section{Función y misión}

"Para que las vocaciones de Dios resuenen y hallen respuesta". Responder a una llamada de Dios siempre implicará una misión y una función, pero sin que la segunda ahogue a la primera.

$P V$, ayudar al creyente "al descubrimiento y asunción de la propia responsabilidad en la Iglesia" (nvnE, n. 28). La persona vocacionada ha de descubrir su misión, aunque luego ésta implique también el desarrollo de una función.

Por ello hemos de preguntarnos si los carismas responden a situaciones de hoy. Se precisa una revisión de las necesidades reales y las respuesta que la Iglesia desde Dios ha ido dando a lo largo de la historia. Esas necesidades pueden ser universales y de todo tiempo o muy particulares y concretas. Nos pueden las inercias de lo que ha ido haciendo en el pasado y ese peso ahoga muchos planteamientos vocacionales.

\section{La verdad completa}

Las vocaciones de Dios no resuenan porque no acabamos de decir y vivir la Verdad, toda la Verdad. Hemos de ser una voz más en el mundo, 
pero yendo más allá del mero competir con los medios de comunicación. Discernimiento vocacional (nvnE, n. 27). Itinerarios pastorales vocacionales, que provocan una verdadera peregrinación...

- Liturgia/oración

- Comunión eclesial

- Servicio de la caridad> experiencia de gran libertad en Cristo

- Experiencia del amor de Dios

No nos conformemos con ofrecer un producto más en el escaparate. No nos avergoncemos de lo que tiene peor encaje con la mentalidad que nos circunda: banalización de la vida eterna, al no haber pecado, infierno, sombra y noche en la historia. No temer ser radicales (que no extremistas) Llamada más provocadora que consoladora. sentido dramático de la vida del hombre (nvnE, n. 26)

¿Qué es una salvación sin redención? Peligro gnóstico, peligro pelagiano, y de rebote, peligro maniqueo.

$\mathrm{El}$ riesgo de la incomunicación es real, pues las grandes preguntas no hallan un eco, espacio y tratamiento adecuado. ¿Quién es Cristo? ¿Se lo pregunta a fondo la gente?

Formar, proponer una forma, modo de ser en que el joven reconoce su identidad:

- A Jesús (llevar a cabo gestos fuertes, signos inconfundibles, propuestas grandes, proyectos de seguimiento radical (nvnE, n. 36)

- La verdad de su vida (nvnE)

En lugar de ayudar a que se pregunten: ¿Dónde vives?”, les cortamos el paso y suplantamos el papel del Señor y de su Espíritu, diciéndoles: "Ven, que yo te digo dónde vive..." Pero Dios no quiere nietos, sino hijos, huyamos de ese paternalismo disfrazado de muchas maneras.

Necesidad de la profecía, recuperar a Juan el Bautista (Que El crezca y yo disminuya). Indicar la presencia del Otro, y la propia relatividad (nvnE, n. 34).

La verdad completa desde el hombre completo.

La visión más completa y rica de la Verdad revelada, en línea con Dei Verbum 2, que casi equipara revelación y salvación, nos ayuda a no malinterpretar a San Agustín: veritas in interiore homine. Un cristianismo débil y residual lee espontáneamente: veritas in interiore hominis: la verdad no está dentro del hombre, en un sentido físico, como algo que cualquier hombre posee, sino en el hombre interior. 
El joven o la joven que pretendemos invitar, ¿qué recibe en concreto de nosotros? ¿Nuestra mirada responde a la pregunta ¿desde qué Dios vives? Y la mirada no engaña. A veces les llega la dureza y el peso de un yugo (¿yugo ligero?)

El cura, el agente de pastoral, místico y mistagogo, con una capacidad de mostrar y ofrecer una mística que acompaña y alumbra el vivir cotidiano... (o la p.v. es mistagógica, o no es tal pastoral, nvnE, n. 8)

La verdad completa, "vivir a lo grande", desde lo que queda más allá. Identidad escatológica, comenzando del militante cristiano. Más allá de toda ideología. La ideología podemos definirla como un sistema de inmunización ante la realidad que amenaza. La fe es otra cosa.

\section{0. ¿Dónde estamos cada uno?}

Situación de indecisión, encontrar aquella piedra sobre la que está escrito el propio nombre, volver a las fuentes del yo (nvnE)

Labor edafológica, de construcción de verdaderos cimientos, de búsqueda de roca donde basarse, de ir a los cimientos de cada uno, y volver a echar los muros de carga sobre esos sillares inconmovibles que están por debajo.

La urgencia nos ha podido llevar y empujar a un trabajo de lo penúltimo, de lo episódico, de lo operativo. Hoy en día se precisa partir desde dentro, bebiendo del propio pozo.

\section{1. ¿En qué hora estamos?}

"Tiempo difícil y formidable" (nvnE)

Ya no hay tiempo

Todo tiempo es bueno

Toda hora es aprovechable y fecunda

Toda persona nos llega en un "ahora"

Nuevas vocaciones para una nueva Europa. ¿Qué significa eso? 


\section{CUESTIONARIO QUE RESULTA DEL ENCUENTRO.}

Estas cuestiones son para trabajarlas entre los meses de octubre a Marzo, con todas aquellas personas y grupos vinculados en tu diócesis a la pastoral vocacional, o simplemente cuyas características entran en lo que es el promover esa vocacionalidad de la Iglesia de la que habla el documento "Nuevas vocaciones para una nueva Europa": (sacerdotes, pastoral juvenil, catequesis, pastoral universitaria, pastoral familiar, etc).

Vuestras respuestas las enviáis a

seminarios.cee@planalfa.es

Plazo máximo, 31 de Marzo

\section{REVISIÓN}

1. ¿Dónde está insertada la pastoral vocacional en el conjunto de la pastoral de la diócesis? ¿Se dan disfunciones y duplicidades?

2. ¿Qué echan en falta o reclaman de la pastoral vocacional otras instancias pastorales de la diócesis? ¿qué es lo que más valoran?

3. ¿Se salva la "vocacionalidad" de la Iglesia con eso que hacemos?

\section{PROPUESTAS}

4. ¿Qué faltaría en nosotros y en las otras instancias pastorales para que la promoción vocacional se desarrolle en toda su riqueza?

5. ¿Cómo renovar la ilusión, la esperanza y la pasión de quienes tienen la misión de llamar y de provocar la respuesta a la llamada de Dios?

6. ¿Cómo implicar a otros en una pastoral vocacional "ordinaria"?

7. Pasar de una pastoral de experiencias a otra de itinerarios. ¿En qué hemos de cambiar para que eso sea más que una frase?

8. Para que el planteamiento vocacional sea más incisivo y más atractivo, resulte algo natural en el camino de fe...

9. Algunas conclusiones operativas, sugerencias. 